\title{
NOSTALGIA EM EDITORIAIS DA REVISTA FERROVIA: UM ESTUDO DISCURSIVO
}

\author{
Nostalgia in Revista Ferrovia editorials: a discursive study
}

\author{
Alana DESTRI \\ Anselmo LIMA²
}

\begin{abstract}
Resumo: $O$ sentimento de nostalgia é a expressão de saudade por algum aspecto prazeroso do passado ao mesmo tempo em que se deseja retornar àquele momento. Devido ao fato de a nostalgia ser algo inerente ao ser humano, ela permeia os enunciados deste. Logo, se faz relevante compreender esse sentimento do ponto de vista do discurso. Tendo isso em vista, este artigo teve como objeto de estudo o discurso nostálgico analisado a partir de um corpus que compreende 87 editoriais da Revista Ferrovia publicados entre os anos 1935 e 1982. O estudo fundamentase primordialmente na teoria dos gêneros discursivos de Bakhtin. Levando a citada teoria em consideração, o objetivo geral foi observar a forma relativamente estável da manifestação da nostalgia no discurso presente nos editoriais. Como resultado, certo padrão de manifestação foi identificado e descrito, ampliando, assim, a compreensão do fenômeno como algo profundamente discursivo e como traço fundamental do coletivo ferroviário.
\end{abstract}

Palavras-chave: Gênero do discurso. Editorial. Nostalgia. Ferrovia.

\begin{abstract}
The feeling of nostalgia is the expression of longing for some pleasant aspect from the past meanwhile one wishes to return to that moment. Since nostalgia is inherent to the human being, it permeates the men's utterances. Hence it is relevant to understand this feeling by the speech point of view. Considering this, this article had as a study object the nostalgic speech analyzed from a corpus which includes Revista Ferrovia editorials published between the years 1935 and 1982. The study is based primarily on Bakhtin's theory of speech genres. Taking the aforementioned theory into consideration, the overall objective was to observe the relatively stable form of nostalgia manifestation in the editorial speech. As a result, a certain pattern of manifestation was identified and described. Thus, the understanding of the phenomenon was broadened as something profoundly discursive and as a fundamental trait of the railway collective.
\end{abstract}

Keywords: Speech genres. Editorial. Nostalgia. Railway.

\footnotetext{
1 Destri. UTFPR. E-mail: alanadestri@outlook.com. ORCID ID: https://orcid.org/0000-0002-8075-9652 2 Lima. UTFPR. E-mail: selmolima@hotmail.com. ORCID ID: https://orcid.org/0000-0003-1427-2165
} 


\section{Introdução ${ }^{3}$}

Esta pesquisa teve como objeto de estudo a manifestação discursiva da nostalgia. Mais especificamente, tal tema foi analisado a partir de um corpus que compreende editoriais da Revista Ferrovia publicados entre os anos 1935 e 1982. Ao todo se computam 87 editoriais.

Utilizando primordialmente a teoria bakhtiniana de gêneros do discurso aplicada à análise do corpus de editoriais e à temática do sentimento nostálgico, almejou-se aprofundar o conhecimento sobre a forma e o conteúdo das manifestações desse fenômeno psicológico e, com isso, delinear a forma relativamente estável de suas ocorrências. Em outras palavras, a pesquisa visou não só desenvolver o assunto em seu conteúdo histórico e psicológico, mas, principalmente, almejou responder à seguinte pergunta científica: "qual é a forma relativamente estável de manifestação discursiva do sentimento da nostalgia"?

Esse sentimento não se restringe à esfera ferroviária: a nostalgia marca com inegável profusão a relação do ser humano com o social e com o mundo. Por ser algo inerente ao ser humano e, por consequência, algo que permeia seus enunciados, é relevante entendêla do ponto de vista do discurso.

Visto através do ângulo da ferrovia, a pesquisa tocou em assuntos políticoeconômicos que repercutem nos dias de hoje. O caráter saudoso dos ferroviários ainda permanece e encontrar chaves discursivas para entender a complexidade desse fenômeno pode ser um bom caminho para o desenvolvimento profissional destes.

O presente artigo encontra-se segmentado em Metodologia, item no qual foi descrita a sequência de ações realizadas para que a atual pesquisa fosse concretizada; Contexto histórico da ferrovia no Brasil; Fundamentação teórica, em que se apresentam as teorias nas quais a pesquisa se embasou; Análises, etapa que registra o desenvolvimento necessário para o alcance da resposta para a pergunta científica; e, porfim, as Considerações finais. Nesse último item, o resultado do processo é exposto e as contribuições do artigo à esfera científica são salientadas.

\footnotetext{
3 O presente artigo é fruto do trabalho de conclusão de curso intitulado Nostalgia em editoriais da Revista
} Ferrovia: um estudo linguístico-discursivo (2016). 


\section{Metodologia}

A aplicação da metodologia deu-se sobre um corpus que parece nunca ter recebido tratamento analítico de forma psicológica ou discursiva. Esse corpus é formado por 87 editoriais de publicações da Revista Ferrovia lançadas entre 1935 e 1982. A citada revista é publicada em São Paulo pelo Órgão Oficial da Associação de Engenheiros da Estrada de Ferro Santos-Jundiaí (AEEFSJ) e circula "em todas as Estradas de Ferro do Brasil e principais ferrovias da América Latina e entidades afins" (AEEFSJ, 1979, p. 3). Um quadro listando todos os editoriais pertencentes ao corpus encontra-se como Apêndice A.

Partindo disso, o desenvolvimento da pesquisa funcionou em três fases: préanálise, exploração do material e tratamento dos resultados (SILVEIRA; CÓRDOVA, 2009). Na fase de pré-análise, o corpus foi ordenado e explorado por meio de diversas leituras. A seguir, como segunda etapa, foi feito o recorte do corpus com base no grau de importância dos editoriais para responder à pergunta de pesquisa. Dos 87 editoriais, 23 deles apresentavam manifestação de nostalgia como aqui é entendida. Em outras palavras, a nostalgia alcança aproximadamente $26 \%$ dos editoriais. Junto a isso se estipularam regras de organização a fim de compreender como os enunciados selecionados "se organizam e se articulam dinamicamente para constituir uma totalidade significativa" (LIMA, 2014, p. 41).

Dando prosseguimento, para tornar possível um tratamento sólido dos dados, esses foram interpretados à luz do embasamento teórico constituído previamente. Seguindo a proposta bakhtiniana, os enunciados foram analisados em suas "quatro dimensões constitutivas: 1) relação interlocutiva, 2) construção composicional, 3) conteúdo temático e 4) estilo" (LIMA, 2014, p. 41). A partir disso, procurou-se identificar o modo relativamente estável de como o fenômeno da nostalgia se manifesta no corpus.

Para compreender profundamente os enunciados presentes nos editoriais da Revista Ferrovia, objeto deste estudo, foi necessária uma pesquisa de contexto histórico. Isso porque a situação concreta vinculada à interação verbal é de primordial importância para sua compreensão e explicação (BAKHTIN, 2011). Ou seja, deve-se ter conhecimento do contexto em que o enunciado foi criado tendo em vista que o sentido do enunciado é por ele completamente determinado (LIMA, 2014). Observe-se a seguir um rápido panorama da história e desenvolvimento ferroviário no Brasil. 


\section{Contexto histórico da ferrovia no Brasil}

O Brasil do período colonial apresentava graves dificuldades de comunicação terrestre entre o litoral e o interior. Dentre as diversas medidas para a melhoria da comunicação estavam as primeiras linhas ferroviárias. Na metade do século XIV, portanto, iniciou-se a era ferroviária brasileira, pouco antes do advento da cafeicultura paulista (MATOS, 1990).

A primeira linha paulista, a linha Santos-São Paulo, chamada "São Paulo Railway", foi implantada em 1866 com financiamento inglês. No ano seguinte ao da sua fundação, a via foi estendida para chegar até a cidade de Jundiaí. Como a expansão das linhas não era do interesse econômico dos ingleses, o restante das conexões foi fomentado por grandes fazendeiros (MATOS, 1990).

A ferrovia foi um grande agente da transformação da paisagem paulistana. Foi de grande auxílio para a colonização, a agricultura e a indústria, facilitando o desenvolvimento econômico de diversas cidades e fundando outras. Sobretudo, os fatos históricos colaboraram para o deslocamento do centro de maior importância econômica e demográfica do norte para o sul do país (MATOS, 1990).

Em decorrência do advento da rodovia, do declínio da produção de café entre outros fatores, a ferrovia passou a ser considerada, em determinados aspectos, antieconômica. Levando em consideração o declínio econômico e de prestígio, justifica tomar o ano de 1940 como o limite final da "era ferroviária" dando espaço para a "era rodoviária" que representou novos desdobramentos de articulação interna (MATOS, 1990).

\section{Identidade ferroviária}

Com relação à identidade dos trabalhadores da ferrovia, atribui-se o grande orgulho de ser ferroviário à própria natureza do processo de constituição das ferrovias. O trabalhador ferroviário sentia-se privilegiado em trabalhar no primeiro grande empreendimento da engenharia brasileira, sentia o prestígio do "moderno" que se relaciona diretamente ao "progresso", palavra à qual atribuíam valor quase místico naqueles tempos (SOUZA, 1983).

Em contrapartida, Souza (1983) assinala que, em situação de declínio, a “identidade ferroviária" não se manteve por completo dessa maneira. Em 1975, o administrador observa, salvo exceções, uma "organização doente, de um pessoal frustrado, desiludido, egoísta, apático, sem ânimo, sem vida [...]" (SOUZA, 1983, p. 187). 
Com tantas mudanças na organização e no ritmo ferroviário, uma parcela quase total dos atuais profissionais passou a olhar para o passado com saudades profundas. Esta rememoração permeia e direciona em diversos níveis as relações trabalhador-trabalhador e trabalhador-empresa. Logo, torna-se evidente o fato de o coletivo ferroviário ser nostálgico.

Uma vez tendo sido apresentado o contexto sócio-histórico do corpus de pesquisa, torna-se relevante adentrar em aspectos teóricos que norteiam a análise discursiva. Esses aspectos teóricos estão explicitados no capítulo seguinte.

\section{Fundamentação teórica}

Para uma satisfatória compreensão do item Análise, é importante um entendimento prévio de dois arcabouços teóricos distintos: 1) a teoria Bakhtiniana dos gêneros do discurso (2011), seguida de uma aproximação ao gênero editorial; e 2) memória e nostalgia discutidas, principalmente, através de escritos de Svetlana Boym (2007) e Ecléa Bosi (2003).

\section{Os gêneros do discurso}

A teoria dos gêneros discursivos foi desenvolvida por Mikhail Bakhtin e o Círculo e por ele é apresentada principalmente no capítulo "Os gêneros do discurso", integrante da obra Estética da criação verbal (2011). Segundo Bakhtin, a linguagem vincula-se a todos os campos da atividade humana e seus diversos usos só se fazem através dos gêneros discursivos.

Por definição, gêneros discursivos são formas relativamente estáveis de enunciado e "cada campo de utilização da língua elabora seus tipos relativamente estáveis de enunciados" (BAKHTIN, 2011, p. 262). Logo, a abundância desses gêneros é infinita, pois assim também é a abundância de campos de atividade humana. Junto disso, o repertório de gêneros do discurso de determinado campo evolui e se diferencia ao passo que as atividades desse grupo se modificam e se complexificam.

O enunciado é a unidade que compõe os gêneros. Éa unidade real da comunicação discursiva, individual e impossível de ser repetido em todas as suas circunstâncias estruturais e sócio-históricas. Constitui-se de uma ligação indissociável entre 1) o conteúdo temático, 2) o estilo da linguagem e 3) a construção composicional. Levando também em consideração a relação interlocutiva, pode-se dizer que a seleção e construção do enunciado é feita para atender às condições específicas e aos propósitos do campo de atividade no qual o enunciado foi gerado. 
Com relação aos elementos que compõem os enunciados e, consequentemente, os "gêneros do discurso", 1) o conteúdo temático corresponde ao tema ou sentido construído na constituição do discurso. Depende das condições de produção e das necessidades de enunciação; 2) o estilo da linguagem é percebido através das escolhas linguísticas do autor, sua relação com o destinatário, a expressão de seu relacionamento valorativo com o conteúdo; já 3) a construção composicional vincula-se à adoção de um padrão estabelecido de um gênero discursivo.

Afirma-se que todo enunciado é uma resposta a outros, pois o autor leva em consideração os enunciados precedentes quando o produz. Mas não só isso: o enunciado se liga também aos enunciados subsequentes ao antecipar a resposta que será dada por determinado destinatário a seu enunciado. Isso reitera a grande importância do outro na comunicação discursiva. A partir disso, todos os elementos que compõem um gênero discursivo são fortemente influenciados pela concepção típica de destinatário que cada gênero abarca.

Vale assim destacar que os enunciados são feitos sob uma vontade discursiva do indivíduo e esta se realiza na escolha de certo gênero do discurso. Sendo o enunciado algo individual, um enunciado também é uma posição ativa de um indivíduo em um dado campo de atividade humana. Nunca é neutro. Consequentemente as escolhas dos meios linguísticos e do gênero de discurso são definidas pelas ideias do autor do enunciado sobre o objeto e o sentido (BAKHTIN, 2011).

O subitem a seguir trata especificamente do gênero editorial, gênero em foco neste estudo.

\section{Gênero discursivo editorial de revista}

O gênero editorial, principalmente encontrado em jornais e revistas, está profundamente atrelado aos princípios ideológicos defendidos pelo periódico do qual faz parte. Sendo assim, tem como principal função ser porta-voz da opinião da sua empresa ou organização, agindo como conselheiro do leitor sobre variados assuntos. Dada sua notável importância para a revista ou jornal como um todo, geralmente situa-se em lugar de destaque e é escrito por profissionais experientes (MONT'ALVERNE; MARQUES, 2015).

Tratando-se da construção composicional deste gênero, comumente os autores de editoriais focam-se no caráter argumentativo para compor o texto. Para tanto, desenvolve-se uma estrutura dissertativa na qual uma questão é rapidamente apresentada, o desenvolvimento é feito com argumentos e contra-argumentos e, ao final, o ponto de vista do órgão é concluído de forma breve (BÁCCARO; NASCIMENTO, 2007). 
Esse tipo textual específico se torna importante ao passo que, de modo geral, seu conteúdo se vincula com a realidade política e sócio-histórica a nível local ou mundial. Sendo assim, para uma análise satisfatória, é relevante ter conhecimento sobre o contexto de produção dos textos a serem analisados e sobre aquilo de que os produtores destes editoriais almejavam convencer o leitor. Nesses termos, a memória e a nostalgia partilhada coletivamente são importantes fatores como pode-se ver a seguir.

\section{Memória e nostalgia}

Cada classe ou coletivo vive o tempo de forma distinta. E esse tempo vivido é conotado pela cultura e pelo indivíduo. A formação da identidade se dá através do vínculo com esse tempo vivido e este tempo vivido se dá através do vínculo com o passado. Para tanto, a memória não seleciona os fatos de forma aleatória, mas sim a partir de índices comuns. Quando essas memórias são partilhadas por um grupo de pessoas, fortificam-se pela expressão de um significado coletivo (BOSI, 2003).

A memória, dessa forma, é função decisiva na existência. Ela concede a relação do objeto atual com o antigo e, ao mesmo tempo, interfere no fluxo de suas representações. Através da memória, o passado vem à tona na atualidade e se mistura com as percepções imediatas. Com esse poder sobre as percepções atuais, toma todo o espaço da consciência (BOSI, 2003).

Segundo Ecléa Bosi (2003), tal atividade, aplicada a boas lembranças, renova o sujeito mnemônico tanto psiquicamente quanto somaticamente. A autora ainda afirma que "o passado reconstruído não é refúgio, mas uma fonte, um manancial de razões para lutar" (BOSI, 2003, p. 66). Dessa forma, a memória não tem em si apenas o caráter de restauração do passado, mas, de certa forma, tem um caráter gerador de futuro. E é aí que o relembrar nostálgico mostra-se importante em um coletivo de indivíduos de um determinado ofício. A partir de sua memória coletiva, o conjunto de ferroviários avalia o presente e se este não se mostra agradável, olha para o passado desejoso de que o presente e o futuro devolvam algo precioso que foi perdido (BOSI, 2003).

A palavra "nostalgia" foi cunhada pelo médico suíço Johannes Hofer em uma dissertação médica em 1678 (CUNHA, 2013). Nela, a nostalgia era tratada como uma patologia motivada por distância da terra natal. Com o passar do tempo, nostalgia adquiriu um significado mais amplo, como "sentimento de perda e deslocamento", um desejo de voltar a experienciar algo que, por diversos motivos, não pode ser experienciado no presente momento (BOYM, 2007). 
Boym (2007) faz três importantes considerações sobre nostalgia. A primeira é que nostalgia não nega e rejeita o presente, como pode se pensar em senso comum. Ela não está em oposição ao contemporâneo, mas o acompanha, um refletindo-se no outro.

Como segunda consideração, nostalgia é mais do que sua definição inicial de "anseio de retornar a algum lugar". Atualmente, nostalgia pode ser vista como o anseio por uma época diferente - a época da infância, a de tempos mais tranquilos. Aquele que tem nostalgia deseja transformar a história em mitologia privada ou coletiva para revisitar o passado (BOYM, 2007).

Por fim, a terceira consideração é sobre a nostalgia não ser sempre retrospectiva: há a possibilidade de ser prospectiva também. As fantasias do passado, determinadas pelas necessidades do presente, têm um impacto direto sobre o futuro (BOYM, 2007).

Logo, nostalgia é também uma estratégia de sobrevivência. É um mecanismo de defesa em um tempo de mudanças históricas e na vida. Nela se constrói o sentido, o entendimento sobre a impossibilidade de se retornar à época objeto da nostalgia. Se o indivíduo mantém uma postura não reflexiva, há o perigo de a nostalgia gerar confusão entre o atual momento e o tempo ido, agora imaginário (BOYM, 2007).

No presente trabalho, levando em consideração a fundamentação teórica apresentada, não basta o indivíduo ser saudoso para ser nostálgico. Para o enunciado ser considerado de conteúdo nostálgico, este deve, por excelência, retomar um passado positivo e demonstrar desejo de retornar a ele. Essa constatação é de significativa importância para o andamento da análise.

\section{Análises}

Tratando-se de gêneros discursivos na perspectiva bakhtiniana, sabe-se que toda forma relativamente estável de enunciado é composta de 1) conteúdo temático, 2) estilo e 3) construção composicional. Além do mais, todo enunciado é situado sóciohistoricamente, construíd o com determinado propósito interlocutivo. Esses três elementos citados e a relação interlocutiva são intrinsecamente conectados, indissociáveis.

No entanto, tendo em vista a clareza e objetividade, a análise foi segmentada. O próximo subitem trata do conteúdo temático nostálgico exposto nos editoriais. O subitem seguinte ocupa-se do estilo da linguagem nos trechos nos quais se apresenta conteúdo nostálgico. Dando sequência, discute-se a construção composicional na qual a temática e o estilo foram enquadrados. Por fim, o último subitem aborda a questão da relação interlocutiva entre locutor e interlocutor, e do propósito enunciativo do uso da nostalgia nos editoriais da Revista Ferrovia. 


\section{Conteúdo temático}

Sob a perspectiva bakhtiniana, a natureza do fenômeno linguístico passa a ser encarada inserida em sua dimensão histórica, a partir de situações específicas de interação, compreensão e significação. Logo a linguagem é entendida como algo que não é produzido e transmitido no vácuo, mas sempre entrelaçado a uma situação histórica e social concreta (BRAIT, 1997).

Como é de se esperar, o tema dos editoriais da Revista Ferrovia é invariavelmente relacionado à esfera ferroviária. Isto é de se esperar, pois o tema envolve as condições específicas de produção e propósitos enunciativos do autor do texto. Produzido por ferroviários para - primordialmente - ferroviários, a temática dos editoriais dessa revista bimestral circula entre o futuro promissor da ferrovia e a necessidade de reestruturação interna e incentivo externo para que consigam alcançar esse dito futuro.

Para o seguimento, é importante reiterar uma constatação de significativa importância para o andamento da análise. Tal constatação exposta no subitem anterior "Memória e nostalgia" diz que o enunciado, para ser considerado de conteúdo nostálgico, deve retomar um passado positivo e demonstrar desejo de retornar a ele. A segunda edição da revista ferroviária traz um exemplo de editorial de caráter nostálgico. Segue-se um trecho:

[...] vivem saudosos em nossa memória <<os bons tempos $>>$ do monopólio dos transportes ferroviários em nosso país. [...] Naquêles tempos [...] as ferrovias eram procuradas e até imploradas para a obtenção de uma passagem ou vagão para o despacho de mercadorias. [...] $<<$ nos bons tempos $>>$, [as mercadorias] estavam a cargo dos clientes das ferrovias que as procuravam para <<conseguir $>>$ o seu transporte. Porém os tempos foram mudando [...]. Para a redenção do sistema ferroviário nacional devem seus responsáveis encarar as estradas de ferro como emprêsas industriais cujo único produto a oferecer é o transporte [...] (NETTO, 1967, p. 5, grafia da época).

O autor do trecho acima insere no editorial uma memória saudosa, a de quando a ferrovia possuía o monopólio do transporte no país. Esse autor, inclusive, utiliza a palavra "saudosos", tornando explícita a relação que tem com a memória apresentada. Em seguida, atesta que os tempos mudaram e, com isso, as relações econômicas e de procura de frete mudaram também. Observa-se aqui que o primeiro elemento, retomar um passado positivo, foi explicitado. 
O segundo elemento fundamental, o desejo de retorno, é expresso quando o autor verbaliza "para a redenção do sistema ferroviário nacional devem seus responsáveis [...]". Ele traz aqui uma sugestão para ser aplicada no presente, visando um futuro melhor para a rede ferroviária. O autor utiliza o vocábulo "redenção", palavra com acepção de ato ou efeito de remir e remir, por sua vez, está atrelado ao significado de tornar a obter algo (CUNHA, 2013). Ao fazer uso da palavra "redenção", o autor mostra ter no seu discurso uma consciência histórica de que a ferrovia era algo poderoso e que, no momento, precisa remir o espaço de frete perdido, precisa salvar-se da decadência em que se encontra. $O$ futuro almejado não é um futuro qualquer: é um futuro parecido ou igual ao passado.

Voltando-se para a questão do primeiro elemento, o passado nunca é retomado por si só no discurso nostálgico. Logo após "os tempos foram mudando", o autor reproduz no texto aquilo que ele observa no presente e que se põe em divergência com o passado de sucesso. Em todos os editoriais nostálgicos, há uma crítica à atual situação da empresa ferroviária. Esse não é um aspecto exclusivo desse editorial apresentado. De forma geral, em um discurso nostálgico, facilmente se nota a existência de uma relação entre passado e presente. Junto a isso, é importante ressaltar que há sempre intrínseca uma visão de futuro.

A motivação para alcançar os objetivos está tão ligada ao vislumbre do futuro quanto à vontade de reavivar o passado. Levando em consideração a teoria apresentada de Bosi (2003), o editorialista nostálgico não apenas ativa a memória coletiva como forma de restauração do passado, mas essa memória tem a função geradora de futuro visto que, através do enunciado, empolga o coletivo no presente em busca de um futuro.

O fato de o ferroviário ter perfil saudoso não é desconhecido por eles próprios. Há consciência disso e, inclusive, tomam esse traço psicológico como algo presente de forma geral entre os indivíduos dessa classe. A princípio, parecem ser dois os grandes objetos de saudosismo nos editoriais da Revista Ferrovia. O primeiro está no âmbito da ferrovia e o segundo está no âmbito do ferroviário. Estes dois objetos estão intimamente interligados e são fruto de um mesmo objeto de nostalgia: o sentimento de fazer parte de uma instituição de extremado prestígio. Logo, conclui-se que não se tem nostalgia de estruturas, elementos físicos, pessoas. Mas, sim, tem-se nostalgia do sentimento que essas estruturas e pessoas proporcionavam e que no presente, por algum motivo, são incapazes de proporcionar.

Com relação à evolução da manifestação nostálgica atrelada ao tema, há certo padrão definido. Dependendo dos tópicos abordados no total do editorial, a manifestação se dá de forma mais suave ou mais intensa. O editorialista, assim, faz a sua escolha sobre 
rememorar o passado com um aspecto mitológico e heroico ou como um bom modelo a ser seguido. Quando a situação imediata de produção do editorial permite uma visão positiva com relação ao futuro, o editorial nostálgico enfatiza a perspectiva de voltar, deixando relativamente sutil a narração da memória. Quando a situação sócio-histórica confere insegurança e incerteza sobre o futuro da esfera ferroviária, há o fenômeno contrário: ainda se deseja voltar, no entanto, destaca-se a descrição gloriosa do passado.

Considerando isso, a produção do conteúdo temático do editorial guia em mesmas proporções e, de forma recíproca, os demais elementos indissociáveis do enunciado. Tal fato não é diferente para o estilo verbal, segundo elemento do enunciado a ser analisado neste artigo.

\section{Estilo verbal}

Como visto, está presente no processo de elaboração do enunciado a "relação subjetiva emocionalmente valorativa do falante com o conteúdo do objeto e do sentido de seu enunciado" (BAKHTIN, 2011, p. 289). Sendo assim, a relação do sujeito com o conteúdo direciona em diversos graus a escolha dos recursos linguísticos a serem utilizados para compor o enunciado.

Nos editoriais, muito se fala em "espírito ferroviário" e as escolhas lexicais para descrever tal espírito baseiam-se, primordialmente, na imagem quase mítica do ferroviário do passado. Nostálgicos, os editorialistas afirmam que os ferroviários que compartilham desse estado de espírito possuem um "espírito imbatível" (FERREIRA, 1977, p. 5), são uma "'casta' sui gêneris [sic] pela peculiaridade do serviço e pelo grande amor e dedicação que tem ao seu trabalho" (E.G.F.P., 1981, p. 5).

O estilo mantém-se no editorial abaixo. Esse editorial trata de um evento em que um prêmio de "ferroviário do ano" foi dado. É explícita em palavras a saudade que se sente do antigo ferroviário. Também se nota que o editorialista, como voz do coletivo, espera que esse "espírito ferroviário" antigo esteja novamente presente. Um espírito que é suposto que os novos ferroviários lembrem e imitem.

[...] em uma era saudosa, em que o Transporte Ferroviário era o dominante, encontramos homens forjados em aço, com uma dedicação que dificilmente se encontra em outro tipo de profissional. Costuma-se dizer que ferroviário é um estado de espírito, e não profissão, pois o verdadeiro ferroviário coloca na escala das prioridades a ferrovia em primeiro lugar, até mesmo antes da família [...]. Homens afeitos a quaisquer sacrifícios, tecnicamente perfeitos [...]. Novas 
[gerações] se sucedem, mas o espírito dos antigos e saudosos ferroviários estáse [sic] amortecendo, com o passar dos anos. Por isso louvamos esta iniciativa de homenagear a classe ferroviária, que as próximas gerações tentarão imitar e saudosamente lembrar. (E.G.F.P., 1980, p. 5).

O trecho acima evidencia que, em editoriais nostálgicos, o passado normalmente é relatado fazendo escolhas lexicais e valorativas positivas ("era saudosa", "homens forjados a aço", "verdadeiro ferroviário"); o presente é posto em contraste e, portanto, com palavras de cunho negativo ("o espírito [...] está se amortecendo"), e tudo isto se soma com um léxico expectante sobre um futuro tão bom quanto o passado ("próximas gerações tentarão imitar").

Nos editoriais nostálgicos, o passado é sempre de alguma forma rememorado e o comportamento discursivo apresentado acima se repete extensivamente nos demais editoriais. Aliadas a um bom aspecto do passado, são comuns expressões como "os bons tempos" (edição 2), "um dos bons sistemas de transporte do mundo" (edição 22), "pioneira" (edição 58), "anos de ouro" (edição 62).

O presente, por ter mudado, regularmente é exposto com desgosto. Discorrem sobre problemas atuais, suas causas e, certas vezes, sobre a injustiça de a ferrovia ter sido "esquecida". Ao entrar na temática "presente", o autor frequentemente promove uma mudança de estilo e tom dentro do discurso do editorial.

Aproximando-se do final de cada discurso, é comum observar alguma resolução feita sobre o futuro. Essas observações e previsões oscilam entre o discurso otimista e pessimista. Tanto de forma positiva quanto negativa, o futuro esperado é sempre ligado a algum aspecto passado. É expresso que um futuro como o passado está se aproximando ou que dificilmente será atingido. Para que o discurso imprima esse traço de volta ao passado, muitas palavras com o prefixo re-são empregadas. A partícula latina re- é constituinte de um grande número de palavras da língua portuguesa. São utilizadas, principalmente, denotando volta, retorno, repetir (CUNHA, 2013).

Palavras com o mencionado prefixo são encontradas em expressões dos editoriais nostálgicos como "restabelecimento daquele potencial" (edição 22), "revalorizar" (edição 41), "ressurgimento da ferrovia" (edição 78). Existem também expressões que não possuem o re-, mas que imprimem a ideia de retorno de forma igual: "volta do trem" (edição 22), "novo apogeu" (edição 56), "parta novamente para uma era de progresso" (edição 57), "despertar deste 'gigante adormecido"” (edição 67), entre outras. 
É válido deixar claro que nem sempre os movimentos linguísticos descritos até aqui são claramente explícitos. Há casos de desenvolvimento dessas conotações de forma velada, implícita no texto ou em diálogo com editoriais anteriores.

\section{Construção composicional}

No que se refere ao editorial da Revista Ferrovia como um todo, a forma de apresentação se altera de diversas maneiras ao passar dos anos de publicação. Ressaltando a característica relativamente estável do gênero, aqui também se tem como relativamente estáveis as manifestações do sentimento de nostalgia.

Nas manifestações há uma parte fixa e há uma parte móvel na disposição desse fenômeno. Como a nostalgia é também um fenômeno psicológico, ela pode estar presente sem grandes exigências de estrutura em diversos gêneros discursivos. A nostalgia penetra no conteúdo e toma a forma exigida pelo gênero em situação real de comunicação.

Como visto, para o discurso ser considerado nostálgico, este precisa conter dois elementos primordiais: 1) ação de "relembrar o passado" e 2) "almejar um retorno". Ao permear um discurso, nem sempre ambos os elementos da nostalgia se encontrarão em um trecho isolado, mas sim, em certa quantidade das vezes encontram-se dispersos no texto.

No caso específico dos editoriais da Revista Ferrovia, quando os elementos estão dispersos no texto, o primeiro elemento de "relembrar o passado" geralmente se encontra no início do editorial. Com uma breve narração, o editorialista ativa a memória do leitor a fim de prepará-lo para contrastar aquele bom passado com as dificuldades do presente, apresentadas logo a seguir. É meio de aproximar o leitor de sua leitura através do sentimento saudoso partilhado e infundido no discurso.

Ainda sobre a disposição estrutural e composicional dos elementos nostálgicos nos editoriais, quando se observa um trecho em que os elementos da nostalgia estão proximamente coesos, esse trecho normalmente encontra-se no final do editorial. A posição é estratégica para que atue como um último recurso de comoção e persuasão sobre o leitor. A forma como se dá a relação interlocutiva entre locutor e interlocutor do enunciado é o assunto do próximo tópico. 


\section{Relação interlocutiva}

Retomando o que foi visto na fundamentação teórica, o editorial tem a qualidade de representar toda a empresa da qual o periódico faz parte. Sendo assim, o editorialista é porta-voz das suas visões político-ideológicas e seu discurso visa convencer o leitor dessa visão. No caso da Revista Ferrovia, o editorialista representa a AEEFSJ e a grande maioria dos editoriais trata de assuntos de caráter geral sobre a ferrovia brasileira, sobre o coletivo de ferroviários, sobre seus medos e êxitos.

É certo que editoriais são escritos por pessoas importantes daquela comunidade na qual circula a revista ou jornal. Com relação aos editoriais da Revista Ferrovia, esse fato não difere. Os editorialistas são todos engenheiros influentes dentro da empresa.

Assim como qualquer outro enunciado escrito, escreve-se tendo em vista um leitor específico. O indivíduo esperado para fazer a leitura dos editoriais de cunho nostálgico da Revista Ferrovia é o ferroviário nostálgico, alguém que possua o mesmo background histórico e empresarial, que partilhe as mesmas memórias ressignificadas. Isso não se restringe a este caso específico, mas é algo universal: um enunciado nostálgico não atinge seu completo potencial emocional e persuasivo se não for direcionado para alguém que partilhe minimamente do mesmo sentimento de nostalgia.

No caso dos editoriais em questão, o posicionamento do autor com relação ao interlocutor será de ferroviário para ferroviário, de engenheiro ferroviário para ferroviário e o de ferroviário para leigo.

$\mathrm{Na}$ relação interlocutiva ferroviário-ferroviário, tendo em vista a nostalgia compartilhada pelo coletivo, a posição linguístico-discursiva do enunciador comumente é próxima ao leitor e se coloca na mesma posição deste. Troca por diversas vezes o discurso do "eu" pelo do "nós", reafirmando que pertence ao mesmo coletivo do leitor. Junto disso, geralmente incita sentimento de união de classe para que todos juntos alcancem o futuro tão desejado para a ferrovia.

O editorialista, que em todos os casos se encontra na posição de engenheiro, por vezes se coloca em um patamar diferente do leitor. A relação interlocutiva engenheiroferroviário visa ao aconselhamento ideológico e profissional do indivíduo atuante na esfera. Utiliza-se do espaço e da profusão do periódico para disseminar ideias e modos de agir que são do interesse da empresa como um todo.

Nas duas formas de relação interlocutiva supracitadas, a nostalgia é inserida como ferramenta de persuasão. Os velhos tempos são retomados como modelos 
perfeitos a serem seguidos, são tomados como ideal de sucesso. Essa técnica funciona, pois o endereçamento se dá, como já dito antes, a um indivíduo que partilha do mesmo sentimento nostálgico. Sendo assim, quando se trata de um discurso para as massas leigas ou para órgãos públicos ou privados, a relação interlocutiva estabelece uma nova abordagem com relação à nostalgia.

Na relação interlocutiva ferroviário-leigo, há a preocupação com que a nostalgia expressa por eles não seja compreendida por completo pelos leigos, fazendo com que estes olhem para a ferrovia como algo retrógrado. Quando o editorial é endereçado para esse tipo de leitor, os focos de nostalgia limitam-se a tratar da glória e rendimento da ferrovia do passado. Trazem muitos dados atuais e como eles poderiam melhorar com a colaboração de determinado órgão ou governo. E isto visto que a Revista Ferrovia existe para, além de tudo, buscar a atenção dessas instituições para solucionar obstáculos que a classe ferroviária não pode superar sozinha.

\section{Considerações finais}

O objetivo desta pesquisa foi observar a forma relativamente estável de manifestação discursiva do sentimento da nostalgia nos editoriais da Revista Ferrovia. Para alcançar esse objetivo, fez-se necessário um conjunto de procedimentos descrito no capítulo Metodologia. O citado item detalhou as fases de contato com o corpus, levantamento de dados e os passos de análise destes.

Em seguida, no item Contexto histórico da ferrovia no Brasil, reuniram-se informações sobre o contexto situacional de criação dos enunciados, algo de crucial importância para que uma análise discursiva pudesse ser satisfatoriamente feita sobre os editoriais.

A análise, em uma perspectiva bakhtiniana, dividiu-se entre 1) Conteúdo temático; 2) Estilo verbal; 3) Construção composicional e 4) Relação interlocutiva. É válido lembrar que todos esses elementos coexistem inseparavelmente, formando o todo de um enunciado, neste caso, o todo da manifestação da nostalgia.

Em 1) Conteúdo temático, pôde ser observado que em um discurso nostálgico há a relação do indivíduo com o passado, o presente e o futuro. Passado e presente em contraste, almejando um futuro similar ou igual ao passado. Ressalta-se aqui que o tema, o sentido construído, é algo intimamente conectado com o contexto sócio-histórico de produção de cada editorial. 
Com relação ao item 2) Estilo verbal, existem certos padrões de escolhas linguísticas do editorialista para se referir ao passado, presente e futuro. Passado, sempre de forma positiva; presente, de forma negativa, e futuro, sendo otimista ou não, procurando retomar o passado.

Tratando-se de 3) construção composicional, a forma da manifestação da nostalgia molda-se, por ser fenômeno psicológico, ao gênero discursivo no qual está inserido. No caso do editorial, as aparições estão em sua grande maioria no início ou no final do texto. Quando no início, é usado para ativar mnemonicamente o leitor para que, a seguir, compreenda o presente de forma contrastante. Quando no final, é usado como último artifício de sensibilização e persuasão do leitor.

A relação entre o editorialista nostálgico e o leitor é descrita no item 4) Relação interlocutiva. Nesse último item de análise, foi observado como se dão as relações de ferroviário para ferroviário, de engenheiro para ferroviário e de engenheiro para público leigo/órgão público ou privado. A primeira relação visa aproximar-se do leitor como um auxílio à resolução de problemas e incentivador de um espírito de união de classe. A segunda trata de nortear a atividade do ferroviário e, em especial, a dos mais jovens. A terceira, diferentemente das outras duas, tem cautela ao usar a nostalgia e requisita atenção e apoio financeiro do governo e instituições privadas às ferrovias.

Com este trabalho, a manifestação da nostalgia mostrou ser um traço complexo da comunidade ferroviária. Por ser um recurso utilizado em um presente de dificuldades e, até mesmo, doloroso em um sentido psicológico, a compreensão da função e efeito da nostalgia torna-se importante. Pôde-se concluir que a nostalgia não é apenas um mero fenômeno psicológico que se manifesta no discurso como recurso para compor os enunciados editoriais, mas é uma ferramenta. Aqui ela auxilia de forma profunda na composição do sentimento de pertencimento de classe, reforça a memória coletiva, bem como é utilizada na manutenção do grupo para que este se mantenha ativo na busca de um futuro melhor para a ferrovia.

A revista como um todo passou a ser regular a partir da crise da ferrovia. A revista e, em especial, o editorial como porta-voz do coletivo, foram um instrumento construído para buscar vencer aquilo que não podiam resolver por eles mesmos. Fazendo uso da nostalgia como instrumento ideológico, os ferroviários poderiam tentar unir uma classe em busca de um mesmo objetivo, poderiam clarificar a situação da ferrovia e, principalmente, talvez voltar a ter a visibilidade que almejam. 


\section{Referências}

AEEFSJ - Órgão oficial da Associação de Engenheiros da Estrada de Ferro Santos-Jundiaí. Expediente. [Editorial]. Revista Ferrovia, ed. especial, p. 3, 1979.

BÁCCARO, L.; NASCIMENTO, E. L. O gênero editorial na perspectiva do interacionismo sociodiscursivo: o contexto de produção. $V$ Encontro Científico do curso de Letras - o desafio das letras, 5, 2007, Rolândia - PR. Anais do V Encontro Científico do curso de Letras. Rolândia - PR: FACCAR, 2007 [não paginado].

BAKHTIN, M. Os gêneros do discurso. In: BAKHTIN, M. Estética da criação verbal. 6. ed. Tradução Paulo Bezerra. São Paulo: Martins Fontes, 2011. p. 261-306.

BOSI, E. O tempo vivo da memória: ensaios de Psicologia Social. 3. ed. São Paulo: Ateliê Editorial, 2003.

BOYM, S. Nostalgia and its Discontents. The Hedgehog Review, Charlottesville - EUA, n. IX, p. 7-18, 2. tri. 2007. Disponível em: http://www.uib.no/sites/w3.uib.no/files/ attachments/boym_nostalgia_and_its_discontents.pdf. Acesso em: 1 jun. 2016.

BRAIT, E. Bakhtin e a natureza constitutivamente dialógica da linguagem. In: BRAIT, E. et al. Bakhtin, dialogismo e construção do sentido. 2. ed. Campinas: Editora da UNICAMP, 1997. p. 87-98.

CUNHA, A. G. Dicionário etimológico da língua portuguesa. 4. ed. Rio de Janeiro: Lexicon, 2013.

E. G. F. P. Um dia muito especial. [Editorial]. Revista Ferrovia, n. 71, p. 5, mar. 1980.

E. G. F. P. FERROVIÁRIO: um estado de espírito. [Editorial]. Revista Ferrovia, n. 76, p. 5, jan. 1981.

FERREIRA, J. Fim de ano. [Editorial]. Revista Ferrovia, n. 57, p. 5, dez. 1977.

LIMA, A. P. de. Procedimentos teórico-metodológicos de estudo de gêneros do discurso: atividade e oralidade em foco. In: BRAIT, B.; MAGALHÃES, A. S. (org.). Dialogismo: teoria e(m) prática. São Paulo: Terracota Editora, 2014. p. 37-53. 
- Nostalgia em editoriais da Revista Ferrovia: um estudo discursivo

MATOS, O. N. Café e ferrovias: a evolução ferroviária de São Paulo e o desenvolvimento da cultura cafeeira. Campinas: Pontes, 1990.

MONT'ALVERNE, C.; MARQUES, F. P. J. A opinião da empresa no Jornalismo Brasileiro: um estudo sobre a função e a influência política dos editoriais. Estudos em Jornalismo e Mídia, Florianópolis, v. 12, n. 1, p. 121-137, 2015. Disponível em: http://dx.doi.org/10.5007/19846924.2015v12n1p121. Acesso em: 1 jun. 2016.

NETTO, J. S. Uma das causas do déficit [sic] nas ferrovias. [Editorial]. Revista Ferrovia, n. 2, p. 5, ago. 1967.

SILVEIRA, D. T.; CÓRDOVA, F. P. A pesquisa científica. In: GERHARDT, T.; SILVEIRA, D. T. (org.). Métodos de pesquisa. Porto Alegre: UFRGS, 2009. p. 31-42. Disponível em: http:// www.ufrgs.br/cursopgdr/downloadsSerie/derad005.pdf. Acesso em: 28 maio 2016.

SOUZA, R. M. Recursos humanos - 4. Um caso grave de patologia organizacional. In: SOUZA, R. M. Administração integrada. São Paulo: Duas Cidades, 1983. p. 181-188.

COMO CITAR ESTE ARTIGO: DESTRI, Alana; LIMA, Anselmo. Nostalgia em editoriais da Revista Ferrovia: um estudo discursivo. Revista do GEL, v. 16, n. 1, p. 111-131, 2019. Disponível em: https://revistadogel.gel.org.br/

DOI: http://dx.doi.org/10.21165/gel.v16i1.2082

Submetido em: 05/12/2017 | Aceito em: 27/08/2019. 
Apêndice A - Lista do corpus de editoriais da Revista Ferrovia

\begin{tabular}{|c|c|c|c|c|}
\hline Número & Mês & Ano & Título & Autor \\
\hline 1 & 12 & 1935 & Sem título & Anônimo \\
\hline 2 & 08 & 1967 & Uma das causas do deficit ${ }^{4}$ nas ferrovias & NETTO, J.S. ${ }^{5}$ \\
\hline 3 & 07 & 1968 & Legislação obsolêta prejudica o sistema ferroviário & NETTO, J.S. \\
\hline 4 & 11 & 1968 & Ferrovia: problema nacional & NETTO, J. S. \\
\hline 5 & $01 / 02$ & 1969 & Bravos, E.F.S.J.! & NETTO, J.S. \\
\hline 6 & 05/06 & 1969 & A "Sofrerail" na Rêde & NETTO, J. S. \\
\hline 7 & 07/08 & 1969 & O "container" & NETTO, J.S. \\
\hline 8 & $09 / 10$ & 1969 & $\begin{array}{l}\text { Associación Latinoamericana de Ferrocarriles } \\
\text { (ALAF) }\end{array}$ & NETTO, J. S. \\
\hline 9 & $11 / 12$ & 1969 & Enfim, as regionais & NETTO, J. S. \\
\hline 10 & $01 / 02$ & 1970 & A ferrovia deve ser divulgada & NETTO, J. S. \\
\hline 11 & $03 / 04$ & 1970 & A ferrovia no país do automóvel & NETTO, J.S. \\
\hline 12 & 05/06 & 1970 & $\begin{array}{l}\text { Companhia Paulista de Estradas de Ferro, pioneira } \\
\qquad \text { a } 150 \mathrm{~km} / \mathrm{h}\end{array}$ & NETTO, J. S. \\
\hline 13 & $07 / 08$ & 1970 & "A propaganda é a alma do negócio" & NETTO, J. S. \\
\hline 14 & $09 / 10$ & 1970 & Um problema de logística & NETTO, J. S. \\
\hline 15 & $11 / 12$ & 1970 & RFF/AS: rumo ajustado & NETTO, J. S. \\
\hline 16 & $01 / 02$ & 1971 & Publicidade negativa & NETTO, J. S. \\
\hline 17 & $03 / 04$ & 1971 & Para um bom barco, melhor comandante & NETTO, J. S. \\
\hline 18 & $05 / 06$ & 1971 & A grande obra & NETTO, J. S. \\
\hline 19 & 08/09 & 1971 & Vamos diversificar? & NETTO, J.S. \\
\hline 20 & $09 / 10$ & 1971 & "Tráfico de cérebros" & NETTO, J. S. \\
\hline 21 & $11 / 12$ & 1971 & Mil novecentos e setenta e um & NETTO, J.S. \\
\hline 22 & $01 / 02$ & 1972 & O trem... outra vez & NETTO, J. S. \\
\hline 23 & $03 / 04$ & 1972 & Ferrovia \& criatividade & NETTO, J.S. \\
\hline 24 & 05/06 & 1972 & Auto-suficiência prejudicial & NETTO, J. S. \\
\hline 25 & 07/08 & 1972 & Boas vindas, Sr. Presidente & NETTO, J.S. \\
\hline
\end{tabular}

4 A grafia original de todos os títulos dos editoriais foi respeitada.

5 O sombreado cinza presente em certas linhas da lista indica que o editorial em questão foi classificado como nostálgico. 
- Nostalgia em editoriais da Revista Ferrovia: um estudo discursivo

\begin{tabular}{|c|c|c|c|c|}
\hline 26 & $09 / 10$ & 1972 & É imprescindível o lucro? & NETTO, J. S. \\
\hline 27 & $11 / 12$ & 1972 & Recuperação em perspectiva & NETTO, J.S. \\
\hline 28 & $01 / 02$ & 1973 & $\begin{array}{l}\text { Santos-Jundiaí, Transporte \& adestramento de } \\
\text { pessoal }\end{array}$ & Anônimo \\
\hline 29 & $03 / 04$ & 1973 & Metropolitano Paulistano & NETTO, J.S. \\
\hline 30 & 05/06 & 1973 & Cuidado com o estol & NETTO, J.S. \\
\hline 31 & 07/08 & 1973 & "Integração para passageiros" & NETTO, J.S. \\
\hline 32 & $09 / 10$ & 1973 & A encruzilhada & NETTO, J. S. \\
\hline 33 & $11 / 12$ & 1973 & Efetiva implantação do sistema regional & NETTO, J.S. \\
\hline 34 & $01 / 02$ & 1974 & A barreira desafiante & NETTO, J.S. \\
\hline 35 & $03 / 04$ & 1974 & Metrô $x$ rede & NETTO, J. S. \\
\hline 36 & $05 / 06$ & 1974 & Metrô x ferrovia: capítulo II & NETTO, J. S. \\
\hline 37 & $07 / 08$ & 1974 & O verdadeiro gargalo & NETTO, J. S. \\
\hline 38 & $09 / 10$ & 1974 & Integrar para resolver & NETTO, J.S. \\
\hline 39 & $11 / 12$ & 1974 & Programa de desenvolvimento ferroviário & NETTO, J. S. \\
\hline 40 & $01 / 02$ & 1975 & Nossa "ferrovia" também melhora & NETTO, J. S. \\
\hline 41 & $03 / 04$ & 1975 & Investimento tambem abrange o pessoal & NETTO, J. S. \\
\hline 42 & $05 / 06$ & 1975 & PESSOAL: mais qualidade e menor quantidade & NETTO, J.S. \\
\hline 43 & $07 / 08$ & 1975 & Colapso! & NETTO, J. S. \\
\hline 44 & $09 / 10$ & 1975 & A hora é de somar & NETTO, J.S. \\
\hline 45 & $11 / 12$ & 1975 & "Nossos agradecimentos" & PIRAJÁ, B. \\
\hline 46 & $01 / 02$ & 1976 & Um objetivo de grande alcance social & PIRAJÁ, B. \\
\hline 47 & $03 / 04$ & 1976 & Pé no freio... & PIRAJÁ, B. \\
\hline 48 & $05 / 06$ & 1976 & Que país é este... & PIRAJÁ, B. \\
\hline 49 & $07 / 08$ & 1976 & Quantidade e qualidade & PIRAJÁ, B. \\
\hline 50 & $09 / 10$ & 1976 & Decepção e desistímulo & PIRAJÁ, B. \\
\hline 51 & $11 / 12$ & 1976 & Fim de ano. Novas esperanças & PIRAJÁ, B. \\
\hline 52 & $01 / 02$ & 1977 & Acelerar & PIRAJÁ, B. \\
\hline 53 & $03 / 04$ & 1977 & Despedida & PIRAJÁ, B. \\
\hline 54 & $05 / 06$ & 1977 & Valorização do engenheiro & FERREIRA, J. \\
\hline 55 & 07/08 & 1977 & Valorização do engenheiro - II & FERREIRA, J. \\
\hline 56 & $09 / 10$ & 1977 & Vinte anos de rede & FERREIRA, J. \\
\hline
\end{tabular}




\begin{tabular}{|c|c|c|c|c|}
\hline 57 & $11 / 12$ & 1977 & Fim de ano & FERREIRA, J. \\
\hline 58 & $01 / 02$ & 1978 & Pioneirismo & FERREIRA, J. \\
\hline 59 & $03 / 04$ & 1978 & Criar: função do engenheiro & FERREIRA, J. \\
\hline 60 & $05 / 06$ & 1978 & Renovação & FERREIRA, J. \\
\hline 61 & $07 / 08$ & 1978 & "O jogo terminou" & FERREIRA, J. \\
\hline 62 & $09 / 10$ & 1978 & Hierarquia & FERREIRA, J. \\
\hline 63 & $11 / 12$ & 1978 & Final & FERREIRA, J. \\
\hline 64 & $01 / 02$ & 1979 & Parabéns e boas findas & MUNIZ, W. \\
\hline 65 & $03 / 04$ & 1979 & A grande chance & MUNIZ, W. \\
\hline 66 & $05 / 06$ & 1979 & Em busca de uma nova imagem & MUNIZ, W. \\
\hline 67 & $07 / 08$ & 1979 & Por que? & Anônimo \\
\hline 68 & $09 / 10$ & 1979 & E por falar em burocracia... & Anônimo \\
\hline 69 & $11 / 12$ & 1979 & A ferrovia dos meus sonhos & E.G.F.P. \\
\hline 70 & $01 / 02$ & 1980 & Anos 80 - a década ferroviária & E.G.F.P. \\
\hline 71 & $03 / 04$ & 1980 & Um dia muito especial & E.G.F.P. \\
\hline 72 & $05 / 06$ & 1980 & A integração de transportes e o "espírito latino" & E.G.F.P. \\
\hline 73 & $07 / 08$ & 1980 & Volta à ferrovia & E.G.F.P. \\
\hline 74 & $09 / 10$ & 1980 & Era uma vez... & E.G.F.P. \\
\hline 75 & $11 / 12$ & 1980 & Eureka: estão redescobrindo a ferrovia & E.G.F.P. \\
\hline 76 & $01 / 02$ & 1981 & FERROVIÁRIO: um estado de espírito & E.G.F.P. \\
\hline 77 & $03 / 04$ & 1981 & A volta aos trilhos & E.G.F.P. \\
\hline 78 & $05 / 06$ & 1981 & Ressurge a ferrovia & EGAB \\
\hline 79 & $07 / 08$ & 1981 & A.L.A.F. & EGAB \\
\hline 80 & $09 / 10$ & 1981 & O novo "condottiere" da SR.4 & E.G.F.P. \\
\hline 81 & $11 / 12$ & 1981 & Ideal & EGAB \\
\hline 82 & $01 / 02$ & 1982 & $\begin{array}{l}\text { Propriedades e especialização do transporte } \\
\text { ferroviário }\end{array}$ & EGAB \\
\hline 83 & $03 / 04$ & 1982 & A crise econômica e os investimentos ferroviários & EGAB \\
\hline 84 & $05 / 06$ & 1982 & $\begin{array}{l}\text { Um sonho se torna realidade: divisão especial de } \\
\text { subúrbios de São Paulo }\end{array}$ & E.G.F.P. \\
\hline 85 & $07 / 08$ & 1982 & A ferrovia na era da cibernética & E.G.F.P. \\
\hline 86 & $09 / 10$ & 1982 & "Progresso" & EGAB \\
\hline 87 & $11 / 12$ & 1982 & Superar com otimismo & EGAB \\
\hline
\end{tabular}

